\title{
TINJAUAN DEBIT PADA SUMUR AIR TANAH BERBASIS POMPA AIR TENAGA SURYA
}

\author{
Muh. Taufik Iqbal ${ }^{1)}$ dan Kushari $^{2)}$ \\ 1) Politeknik Negeri Ujung Pandang Makassar, Indonesia \\ Email : muhtaufikiqbal@poliupg.ac.id \\ ${ }^{2)}$ Politeknik Negeri Ujung Pandang Makassar, Indonesia \\ Email : marthaonapa@yahoo.co.id
}

\begin{abstract}
To optimize the planting of rice plants, groundwater is used as a source of water so that the water needs for agricultural land can be met. Groundwater, which is a source of water, is known to contribute greatly to agricultural production, especially in the dry season. The long-term goal of this research is to increase groundwater discharge using a water pump as a controller of water distribution, alternative energy in the form of solar energy is used to drive the pump engine. During this time the pump is driven by an oil-fueled engine (BBM) which produces CO2 emissions into the air. The use of non-fuel alternative energy is expected to help reduce CO2 emissions so far. The research method begins with a survey and field survey conducted by the groundwater irrigation network in the ParePare district. then search along ground waterways and mark using GPS. Measuring discharge and analyzing the performance of solar water pumps.
\end{abstract}

Keywords-irrigation, groundwater, solar power

\section{PENDAHULUAN}

Di beberapa desa di kota Pare-pare mengalami kekurangan ketersediaan air untuk lahan pertanian[1]. Untuk mendapatkan air, petani di desa tersebut menggunakan mesin pompa air tanah berbahan bakar minyak [2]. Penggunaan energi alternatif non BBM diharapkan membantu penurunan emisi $\mathrm{CO} 2$ yang selama ini terjadi [3]. Penggunaan sel surya dapat mengubah cahaya matahari menjadi energi listrik dengan catatan bahwa faktor cuaca akan mempengaruhi sistem ini. Tegangan dan arus mulai dihasilkan pada pukul 06.00 pagi, terus meningkat, sampai pada puncaknya pukul 12.00 tengah hari dan selanjutnya menurun hingga sore hari[4]. Penerapan teknologi ini akan dilakukan dalam sebuah demplot dengan tujuan mendapatkan sebuah model pemanfaatan irigasi air tanah berbasis pompa air tenaga surya [5][6].

\section{METODE PENELITIAN}

A. Tahapan-Tahapan Penelitian

Tahapan-tahapan penelitian ini meliputi pengumpulan data, survey lapangan, analisis data sampai dengan pembuatan laporan hasil penelitian.

Adapun prosedurnya sebagai berikut : Tahap I : Persiapan / pendahuluan meliputi :

a. Permohonan perizinan secara tertulis kepada instansi pengelola irigasi.

b. Suvey / peninjauan lapangan.

Tahap II : Pengambilan data Primer terdiri dari :

a. Pengukuran debit.

b. Pumping Test.

Tahap III pengumpulan data sekunder

Tahap IV pengolahan data

Pembuatan Laporan

B. Lokasi Penelitian

Penelitian dilakukan di Jaringan Irigasi Air Tanah Kabupaten Pare-

Pare. 
C. Alat dan software yang digunakan

Peralatan dan perlengkapan yang digunakan dalam pumping test adalah:

- Alat Pengukur Muka Air

- Alat ukur panjang/horizontal yaitu meteran
- Stop watch

- Formulir isian dan alat tulis

- Alat penyipat datar

\section{Fishbone Penelitian}

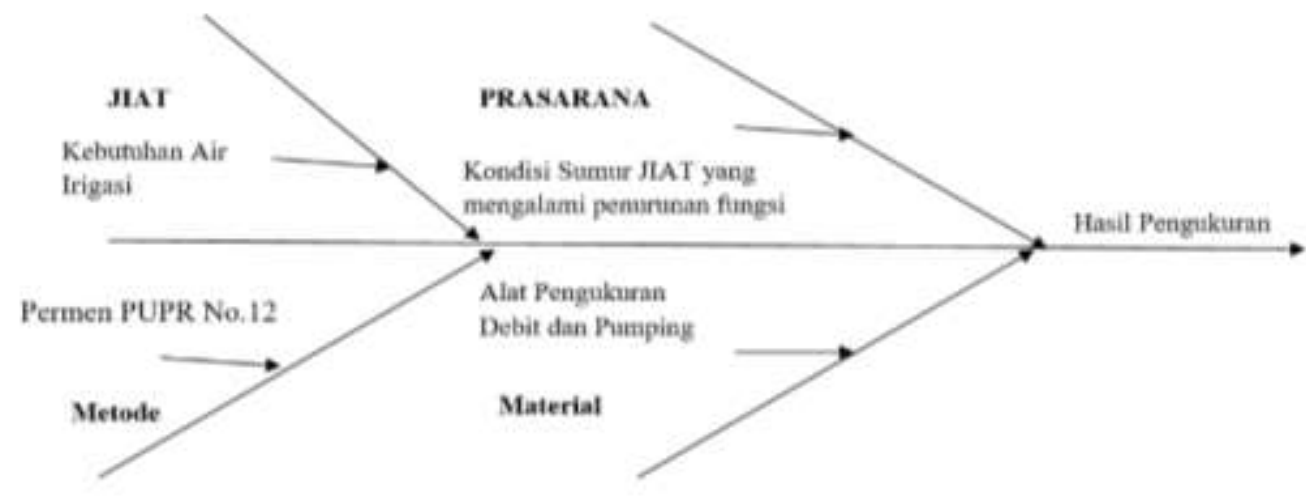

Gambar 1. Diagram fishbone penelitian

\section{HASIL DAN PEMBAHASAN}

A. Spesifikasi Teknis Pompa

Pompa yang digunakan adalah pompa submersible, lengkap dengan motor listrik dan peralatan lain yang diperlukan. Pompa ini akan digerakkan dengan power tenaga surya/PLTS sebagai sumber daya utama berdasarkan spesifikasi teknis yang telah ditentukan. Kapasitas pompa tidak boleh lebih dari 1,5 ltr/det yang memenuhi kondisi sebagai berikut:

Tabel 1. Spesifikasi Teknis Pompa Air Tenaga Surya

No. Uraian Komponen dan Spesifikasi Teknis

Satuan Volume

Ket.

Pengadaan dan Pemasangan Pompa Tenaga Surya Kap. 20.000-25.000 ltr/hari-Head 50-70 m

$1 \quad$ Pengadaan pompa submersible dan ass lengkap

Set 20

dengan accessories dan proteksi

- Pompa submersible

- AC/DC electric motor

- Inverter built in

- Proteksi over load built in

- proteksi thermal

- Proteksi dry running

2 Pengadaan Modul Solar Sel lengkap dengan ass,

Set

Solar Module Cristaline Minimum 1560 Wp, 
Jurnal Teknik Hidro

Volume 12 Nomor 2, Agustus 2019

Terminal Socket Junction Box

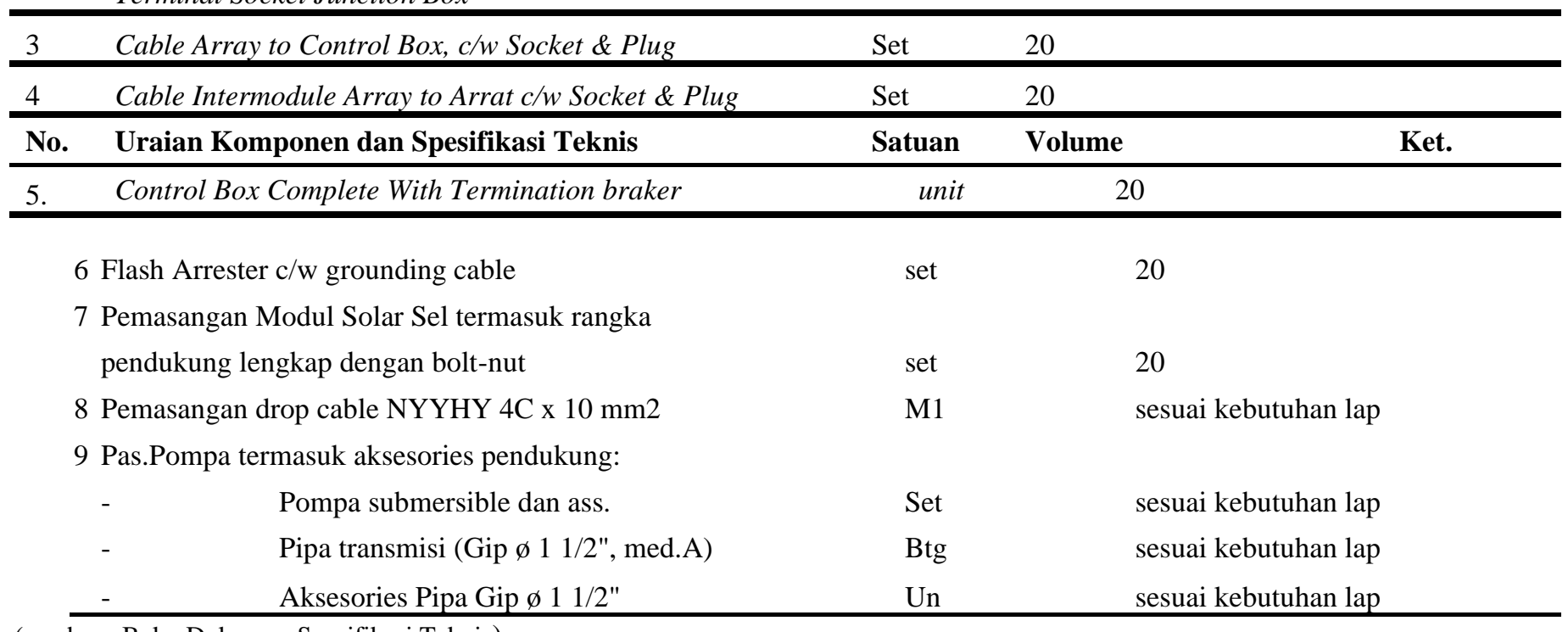

(sumber : Buku Dokumen Spesifikasi Teknis)

\section{B. Peta Topografi}

Pengukuran luas sawah dilakukan menggunakan GPS Juno dengan cara melakukan tracking, hal pertama yang dilakukan adalah menentukan titik pompa setelah itu melakukan tracking berdasar luas sawah yang akan diukur. Berdasarkan pengukuran luas dengan menggunakan GPS Juno didapatkan data-data yang disajikan pada tabel berikut:

Tabel 2. Data koordinat Pompa Air Tenaga Surya

\begin{tabular}{|c|c|c|c|c|c|c|c|c|}
\hline \multirow[b]{2}{*}{ No. } & \multirow[b]{2}{*}{ Lintasan } & \multicolumn{2}{|c|}{ Kota Parepare } & \multirow{2}{*}{$\begin{array}{l}\text { Elv. } \\
\text { (m) }\end{array}$} & \multirow{2}{*}{$\begin{array}{c}\text { Luas sawah } \\
\text { yang dialiri } \\
\left(\mathrm{m}^{2}\right)\end{array}$} & \multicolumn{2}{|c|}{ Koordinat } & \multirow[b]{2}{*}{ Ket. } \\
\hline & & Kelurahan & Kecamatan & & & Easting & Northing & \\
\hline 1 & Bacukiki & $\begin{array}{c}\text { Wt. } \\
\text { Bacukiki }\end{array}$ & Bacukiki & 24 & $13.542,41$ & 794958.04 & 9551105.65 & $\begin{array}{l}\text { Pompa } \\
\text { Titik } 1\end{array}$ \\
\hline 2 & Abbanuangnge & $\begin{array}{c}\text { Wt. } \\
\text { Bacukiki }\end{array}$ & Bacukiki & 23 & $10.079,96$ & 793798.58 & 9549706.82 & $\begin{array}{l}\text { Pompa } \\
\text { Titik } 2\end{array}$ \\
\hline 3 & Mangimpuru & $\begin{array}{c}\text { Wt. } \\
\text { Bacukiki }\end{array}$ & Bacukiki & 20 & $13.328,88$ & 793187.21 & 9549539.34 & $\begin{array}{l}\text { Pompa } \\
\text { Titik } 3\end{array}$ \\
\hline
\end{tabular}

(sumber: Hasil Pengukuran GPS Trimble Juno 5 series)

Data koordinat dari GPS Juno di download menggunakan aplikasi data transfer atau via bluetooth, kemudian diinput di Google Earth dan Microsoft Excel untuk pengolahan datanya, pembuatan peta topografi menggunakan aplikasi ArcGIS dan Google Earth. Adapun hasil dari digitasi dari peta tersebut ialah sebagai berikut: 


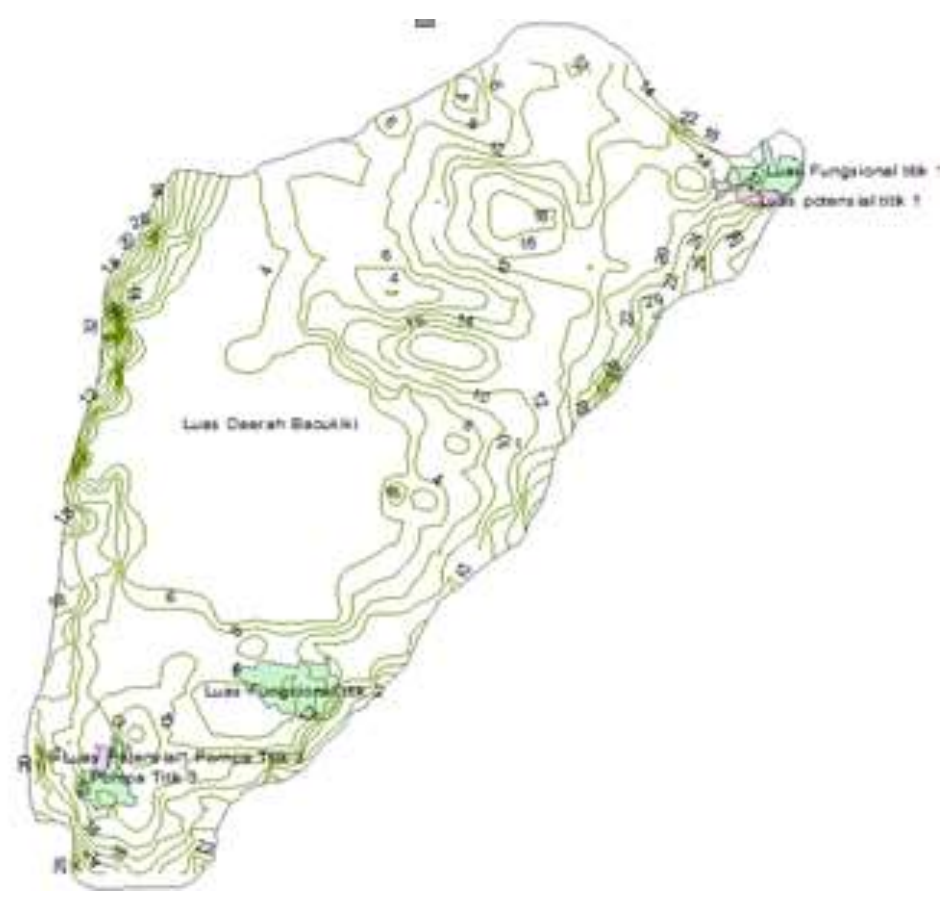

\section{Debit Aliran Pompa}

Untuk mengetahui jumlah debit yang dikeluarkan oleh pompa air, maka kami melakukan perhitungan debit dilapangan dengan

\section{Gambar 2 Peta Luasan Sawah}

menggunakan ember sebagai alat acuan pengukuran. Adapun data yang kami peroleh dari perhitungan debit yaitu :

1) Debit Pompa Titik I

Tabel 3. Hasil Pengukuran Debit Rata-Rata Pompa Titik 1 Hari ke-1

\begin{tabular}{|c|c|c|c|c|}
\hline \multirow{2}{*}{ No. } & \multicolumn{2}{|c|}{ Waktu Pengukuran } & \multirow{2}{*}{$\begin{array}{l}\text { Volume Ember } \\
\text { (liter) }\end{array}$} & \multirow{2}{*}{$\begin{array}{l}\text { Debit Rata-Rata } \\
\text { (ltr/detik) }\end{array}$} \\
\hline & Hari/Tgl & Jam & & \\
\hline \multirow[t]{12}{*}{1} & Jumat, 12 April 2019 & $06.00-07.00$ & 18 & 0,12 \\
\hline & & 07.00-08.00 & 18 & 0,36 \\
\hline & & 08.00-09.00 & 18 & 0,66 \\
\hline & & $09.00-10.00$ & 18 & 0,9 \\
\hline & & $10.00-11.00$ & 18 & 1,05 \\
\hline & & $11.00-12.00$ & 18 & 1,35 \\
\hline & & $12.00-13.00$ & 18 & 1,2 \\
\hline & & $13.00-14.00$ & 18 & 0,81 \\
\hline & & $14.00-15.00$ & 18 & 0,9 \\
\hline & & $15.00-16.00$ & 18 & 0,45 \\
\hline & & $16.00-17.00$ & 18 & 0,18 \\
\hline & & $17.00-18.00$ & 18 & 0,06 \\
\hline
\end{tabular}




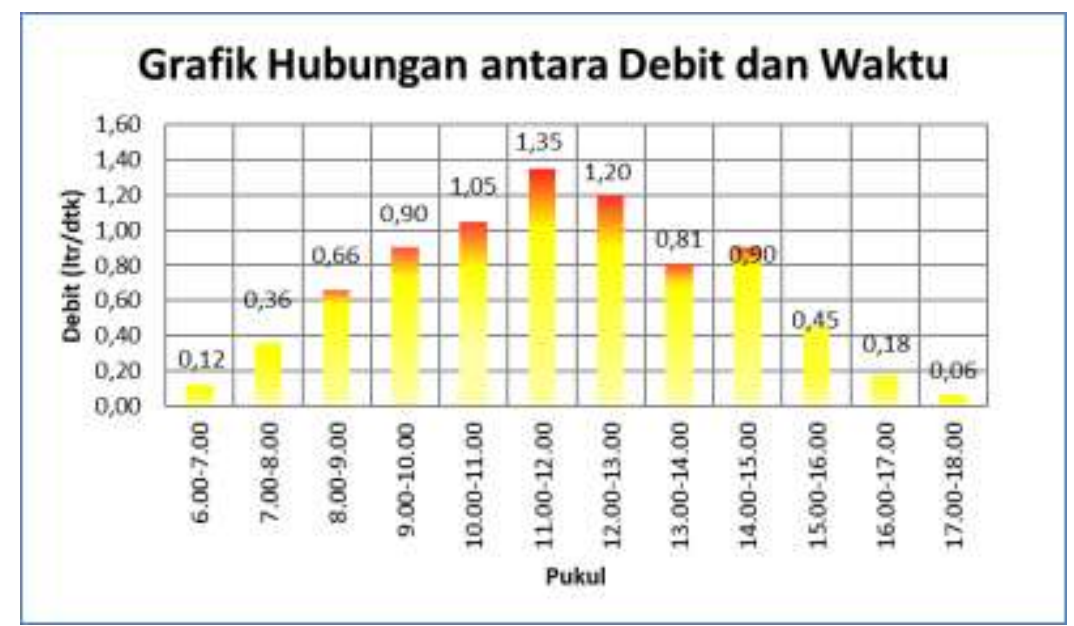

Gambar 3. Hubungan antara Debit dan Waktu

1) Debit Pompa Titik II

Tabel 4. Hasil Pengukuran Debit Rata-Rata Pompa Titik 2 Hari ke-1

\begin{tabular}{cccc}
\hline \multirow{2}{*}{ No. $\quad$ Hari/Tgl } & Jam & $\begin{array}{c}\text { Volume Ember } \\
\text { (liter) }\end{array}$ & $\begin{array}{c}\text { Debit Rata-Rata } \\
\text { (ltr/detik) }\end{array}$ \\
\hline 1 Jumat, 12 April 2019 & $06.00-07.00$ & 18 & 0,06 \\
& $07.00-08.00$ & 18 & 0,075 \\
& $08.00-09.00$ & 18 & 0,12 \\
& $09.00-10.00$ & 18 & 0,135 \\
& $10.00-11.00$ & 18 & 0,15 \\
& $11.00-12.00$ & 18 & 0,15 \\
& $12.00-13.00$ & 18 & 0,18 \\
& $13.00-14.00$ & 18 & 0,18 \\
& $14.00-15.00$ & 18 & 0,15 \\
& $15.00-16.00$ & 18 & 0,09 \\
& $16.00-17.00$ & 18 & 0,03 \\
& $17.00-18.00$ & 18 & 0,009 \\
\hline
\end{tabular}

2) Debit Pompa Titik III

Tabel 5. Hasil Pengukuran Debit Rata-Rata Pompa Titik 3 Hari ke-1

\begin{tabular}{ccccc} 
No. & \multicolumn{2}{c}{ Waktu Pengukuran } & $\begin{array}{c}\text { Volume Ember } \\
\text { (liter) }\end{array}$ & $\begin{array}{c}\text { Debit Rata-Rata } \\
\text { (ltr/detik) }\end{array}$ \\
\hline Humat, 12 April 2019 & Jam & 8,04 & 0,13 \\
& $06.00-07.00$ & 8,04 & 0,36 \\
& $07.00-08.00$ & 8,04 & 0,64 \\
& $08.00-09.00$ & 8,04 & 0,74 \\
& $09.00-10.00$ & 8,04 & 0,90
\end{tabular}




\begin{tabular}{ccc}
$11.00-12.00$ & 8,04 & 0,99 \\
$12.00-13.00$ & 8,04 & 0,88 \\
$13.00-14.00$ & 8,04 & 0,66 \\
$14.00-15.00$ & 8,04 & 0,48 \\
$15.00-16.00$ & 8,04 & 0,29 \\
$16.00-17.00$ & 8,04 & 0,24 \\
$17.00-18.00$ & 8,04 & 0,11 \\
\hline
\end{tabular}

\section{KESIMPULAN}

Berdasarkan hasil penelitian yang telah dilakukan, maka debit rata-rata pompa air tenaga surya yang dihasilkan selama 3 hari berturut-turut untuk Pompa Titik 1 yaitu 0,617 ltr/detik dengan luas sawah yang dialiri adalah 13.542,41 $\mathrm{m}^{2}$, untuk Pompa Titik 2 yaitu 0,107 ltr/detik dengan luas sawah yang dialiri adalah $10.079,96 \mathrm{~m}^{2}$, dan untuk Pompa Titik 3 yaitu 0,535 ltr/detik dengan luas sawah yang dialiri adalah 13.328,88 $\mathrm{m}^{2}$.

\section{DAFTAR PUSTAKA}

[1] L. Somantri, "Kajian Mitigasi Bencana Longsor Lahan Dengan Menggunakan Teknologi Penginderaan Jauh," Semin. Ikat. Geogr. Indones., pp. 1-10, 2008.

[2] N. Richana and Suarni, "Teknologi Pengolahan Jagung," Balai Penelit. Tanam. Serealia, Maros, 2005.

[3] S. Sirait, S. K. Saptomo, and M. Y. J. Purwanto, "Rancang Bangun Sistem Otomatisasi Irigasi Pipa Lahan Sawah Berbasis Tenaga Surya," J. Irig., 2018.

[4] B. Harsoyo, "Review modeling hidrologi das di indonesia," J. Sains Teknol. Modif. Cuaca, 2010.

[5] H. D. S. Muhamad, M. Undang, A. Oman, and I. I. Munib, "Sebaran akuifer dan pola aliran air tanah di Kecamatan Batuceper dan Kecamatan Benda," Indones. J. Geosci., vol. 1, no. 3, pp. 115$128,2006$.

[6] M. Abduh, "Studi kapasitas debit air tanah pada akuifer tertekan di kota malang," pp. 71-80, 2012. 